\title{
The place of emotions while inspecting schools: reflections of two Ofsted inspectors
}

\begin{abstract}
This article investigates the role of emotions of inspectors while inspecting schools as reported by inspectors themselves within an education context of increased accountability that arguably privileges rationality over emotions. The study is built on an emotion management framework that regards emotions not only as unavoidably natural and intimately linked to 'rational' judgements that people make, but also that such judgements are social constructions used to regulate expression of emotions. In-depth interview data of one retired and another, semiretired Office for Standards in Education (Ofsted), inspectors were thematically analysed to assess the extent to which their emotions formed part of school inspections. In the absence of an officially sanctioned narrative of inspectors' emotions during inspections, two kinds of self-prescribed emotions emerged as key findings: emotions for accountability, to which inspectors gave expression, and emotions for improvement, that they suppressed. For an inspection body that needs to ensure both accountability and improvement of schools to justify its viability, these research claims open up a new area of discussion that should lead to a review of inspection body's stance on emotions and individual inspectors' self-reflections on the moral as well as professional obligation to pursue both emotions for accountability and improvement.
\end{abstract}

Key words: Emotions; intellect; school accountability; school improvement; school inspection; school leadership

\section{Introduction}

It is becoming more common for nations to put in place some form of mechanism to monitor the quality of their education systems. In England and Wales, such a role falls within the remit of the Office for Standards in Education (Ofsted) whose influence can be felt beyond the English and Welsh borders (Palmer 1990; CfBT 2015). Having gone global, inspection methodologies will be caught up in various cultural assumptions that if not questioned, or reflected upon, run the risk of preventing the sought after success both for the English school inspections and other inspection systems rooted in different cultural assumptions. One culturally related concept that is the focus of this study is 'emotions' and the role they play during school inspections.

This paper, therefore, begins with a brief discussion about Ofsted which culminates in the identification of the organisation's longstanding aims of school accountability and school improvement that are appreciated variably. The study then puts forward and elaborates on four propositions that have arguably defined the work of Ofsted. Those propositions are that 1) Ofsted is yet to convincingly fulfil its role as an instrument for school improvement, 2) the 
work of Ofsted is predominantly defined by intellect/reason rather than the emotions/feelings, 3) the overemphasis on intellect is consistent with the overall European social context and 4) when emotions in relation to inspections in England are talked about, they often refer to the emotional impact that Ofsted inspectors have on those they inspect.

Hence, the pertinence of the research question 'to what extent do inspectors' emotions form part of the inspection process within accountability regime of neo-liberal project and what lessons could be learnt nationally and internationally from this research project? Ashforth and Humphrey's (1995) theoretical framework of emotion management in organisations within the dramaturgical theories of emotions (Turner and Stet 2006) is discussed before giving a brief description of the methodology adopted for the study. A thematic discussion of the data obtained has led to the distinction between emotions for accountability and emotions for improvement as integral components of the exercise of inspecting schools. While the former is given expression, the latter is suppressed which has led the author to suggest a possible reason for the diminished effectiveness of Ofsted as a school improvement institution. The article finishes with a reflection on the implications of the above main claims and the way ahead for inspections in England and in other places which may be rooted within a different cultural heritage.

Ofsted: creation, organisation, appeal and objectives

Ofsted is a British government non-ministerial department which gained its full recognition under the 1992 Education School Act as a result of the 1988 Education Reform Act for England and Wales. However, the practice of inspecting educational institutions can be traced back to 1838 (Maclure 2000). Organised once along religious denominational lines before being run by local education authorities, Baxter $(2014,21)$ describes the centralised Ofsted today as 'a complex multi-layered organisation; in the current regime 2,700 inspectors are contracted and trained by three agencies Centre for British Teachers (CfBT) Education Trust for the North of England, SERCO Education and Children Services for the Midlands and Tribal Group for the South of England); they in turn are quality controlled by the 400 full-time Her Majesty's Inspectors (HMIs) employed directly within Ofsted'.

When what used to be Her Majesty's Inspectorate (HMI) and the local authorities' inspection teams morphed into Ofsted, it represented several things: the close-knit organisation became a complex entity, a national body outsourced its work to private institutions who would then carry out large scale inspections on the cheap, and the production of unprecedented 
amount of data that would enhance the knowledge of how educational institutions operate in order to improve them (Ball 2007; Lee and Fitz 1997; Meikle 1992).

Beyond the differing views about the creation of Ofsted and its subsequent evolution, there is nevertheless the perception that England has longer and more established traditions of school inspection compared to, for example, Germany and Turkey (Dedering and Muller 2011; Gurkan and Deveci 2012). It is not surprising, therefore, that Nigeria, for example, would seek to model its school inspection system following HMI (Palmer 1990). The international standing of Ofsted is much wider and current than a single country like Nigeria that, more than 25 years ago, sought to model its inspection system following HMI. To illustrate this further, let us take the example of CfBT which describes itself as having an 'end to end' global portfolio of consultancy. In places/countries like Abu Dhabi, Brunei, Dubai, India, Jamaica, Kenya, Malaysia, Oman, Somalia, South Africa and United Arab Emirates, CfBT claims to provide advice about strategy as well as organise the conduct of inspections (CfBT 2015). It is likely that among all the 'best' practices being exported, the presumably 'rational' inspection expertise, to be elaborated upon in the next two sections, would be replicated in places outside of England. Longer inspection traditions and a worldwide appeal do not necessarily mean everything about it must be co-opted in a wholesale manner by those seeking to improve their inspection systems.

On the ground, Ofsted is tasked to oversee school inspections which, according to Richards $(2001,656)$, 'involves observing work in schools, collecting evidence from a variety of other sources and reporting judgements'. The current inspection framework is much broader and the inspecting team would form their judgement based on pupils' achievement, quality of teaching, behaviour/safety of pupils, and quality of leadership and management of the school. In doing so, it seeks to be an instrument for accountability and improvement. The objectives of accountability and school improvement have not only remained high on Ofsted's agenda but they have also been subject to mixed reviews. Chapman $(2001,47)$, for example, recognises the successes that Ofsted has had with the following:

It has provided the mechanism to thoroughly audit schools and increase their accountability to all stakeholders. It has also challenged and encouraged a wider debate on sensitive and difficult issues such as educational failure, inner city/urban education and the limiting nature of low expectations. 
Proposition 1: Despite the above successes with regard to accountability, it is now acknowledged that the link between inspections and school improvement, especially in the way of students' results, is yet to be established (Chapman 2001; Rosenthal 2004). In their European study, Ehren and Visscher (2008) advocate for the quality and way feedback are given and implemented as some of the essential aspects of inspections that could lead to school improvement. Inspection methodologies, correlation of perceptions of learning by all including principals, teachers, students and parents, types and frequency of inspection visits, the publication of standards for inspection, as well as sanctions, rewards and interventions have also been identified as vital inputs that could lead to school improvement (Dedering and Muller 2011; Ehren et al. 2013; Ehren and Visscher 2008; Jones and Tymms 2014).

The most recent 2012 Ofsted inspection framework has some significant changes which represent an overt admission by Ofsted that school improvement is an on-going issue with which the institution continues to grapple. The increased focus on students' progress and emphasis on (paired) lesson observations with schools' experienced or senior leadership as well as their inclusion as inspectors in the 'inspector-inspected' partnership (Ofsted 2014) portray Ofsted as much more than a body that makes sure that schools have protocols reflecting official policies in place (Ehren et al. 2013). The inspector-inspected partnership has attracted certain criticisms particularly with regard to the conflation of institutions (inspectorate and school) but, the author's view is that it still represents an attempt to engage with teaching and learning in order for Ofsted to be more of a tool for school improvement (Baxter 2014). Baxter, however, notes that there is no evidence yet to suggest that the wished for partnership/proximity between the inspectors and the inspected is having its intended impact.

The suggestion emerging from data analysis is that a strong commitment to school improvement strategies needs to depart from recognition and implementation of emotions for school improvement. But that is easier said than done, given an inspection regime that, as summed up by proposition 2 in the next section, is predominantly rational.

\section{It's the business of the intellect}

Inspectors are humans who, according to Barret (2006), have an emotional or affective side which differentiates them as humans from animals (Lupton 1998). In psychology, emotions can be defined as 'neurophysiological and psychological reactions that aid in adapting to social coordination problems' (Matsumoto et al. 2008, 58). In counselling the terms emotions and 
feelings are slightly nuanced but as opposed to a person's intellect, the two affective terms are used here interchangeably.

Proposition 2: The contention here is that the work of Ofsted is predominantly defined by the intellect/reason rather than the emotions/feelings. One does not need to look farther to find evidence of the rational nature of Ofsted inspection regimes. One of its aims, for example, is 'to provide parents with an expert and independent assessment of how well a school is performing and help inform those who are choosing a school for their child to attend in future' (Ofsted 2012a, 4). There is certainly a moral and social justice purpose (Brundrett 2014), expressed through the need for identifying good schools for children to attend, to justify the efforts of the inspectors. However, there is a sense here that such moral goal can only be arrived at through 'expert and independent assessment' that is free not only from external control but also emotive influence.

Clarke (2008) has, through what he calls technical, political, social and institutional performance paradoxes, questioned the full autonomy and independence status that is used to make a claim for Ofsted's purely rational and emotionally untainted inspections. The technical paradox centres around the flaws in the methodology employed leading to questionable judgements about schools. The political paradox highlights the conflation of party, government, policy and Ofsted agendas which may compromise claims for independence. The social paradox brings to the fore of the independence argument the identities, interests, experiences and emotions of inspectors. The institutional paradox challenges the closeness between Ofsted and educational institutions that they inspect resulting to 'capture' which undermines capacity for independent judgement. Overall, Ofsted's autonomy may be a contested concept but its rational nature is not. Citing an earlier publication by both Baxter and Clarke (2013), Baxter $(2014,22)$ confirms the view here that 'Ofsted has since its inception been closely associated with a series of rational, highly engineered frameworks, that reflect the neo-liberal project'.

Inspecting is about collecting evidence, measuring them against set standards and publishing them. It is a form of research which involves a systematic study of data, analysis and scrutiny before reaching a conclusion all of which are rational or intellectual activities. By gathering, interpreting, evaluating and reporting, Osfted, like 'any national inspectorate requires clarity about the aims, values and concepts embodied in the system it serves' (Richards 2001b, 657). Clarity presupposes comprehensibility which points to mental and intellectual activities. This is the view that Ofsted as an institution wants to give not only to the wider public but also to aspiring inspectors suggesting that it is embedded in its training processes. 
In defining the profile of the kind of women and men that could be considered as inspectors, Ofsted says: 'Your incisive intellect will be matched by an ability to build rapport and win trust-able to make sound judgments based on your analysis of inspection evidence' (Ofsted, 2013). The inclusion of 'build rapport and win trust' in the above citation may be a reminder that emotions are important in the inspection processes. However, the discourse of incisive intellect and sound analysis of inspection evidence seem to have eclipsed the emotional side of inspection processes.

In an earlier publication that continues to inform the 2012 framework, Ofsted seems to have taken a commitment to engage in the clarity of language used when publishing their reports.

be clear to all its readers, governors, parents, professionals and the public at large; .... use everyday language, not educational jargon, and be grammatically correct; ... use telling examples drawn from the evidence base (of the inspection) to make generalisations understandable and to illustrate what is meant by 'good' or 'poor'; ... employ words and phrases that enliven the report and convey the individual character of the school. (Ofsted, 1999b, 145 also cited in Richards 2012, 252)

It is in this context that the inspecting body requires each inspector to 'be an inspirational and credible communicator, ready to report your findings with confidence' (Ofsted, 2013). While this might mean using appropriate vocabulary that can be understood by various parties (parents, teachers and other interested parties), there is also the need for Ofsted to ensure that clarity and logic are reflected in the way that evidence collected links to the final inspection judgement. Despite the stark reminder that 'inspectors are not simply the equivalent of value-free cameras or video-recorders randomly providing snapshots of schools and classrooms' (Richards 2001b, 656), there is still an apparent 'diminishing' or 'diminished' role of emotions in what is viewed as Ofsted's technicist approach (Jeffrey and Woods 1996) when inspecting schools. This is not to say that inspections are devoid of an emotional dimension as shall be discussed when making proposition 4 . However, there is the need to 'embrace stories of actions within theories of context' (Goodson 2013, 5). The next proposition 3 aims to put forward a plausible historical account in an attempt to explain why intellect seems to have been valued over emotions.

Emphasis on intellect: a brief social context

Proposition 3: Ofsted's overemphasis on 'intellect' is consistent with the view in European social context within which it is located. 
The fact that the place of emotions is hardly evidently articulated in the work of Ofsted (set within neo-liberal accountability regimes) may be a remnant of the creationist religious traditions that portray emotions as able to distort our perception of factual reality, that which pushed the first created humans to commit sin. Within these Stoic religious traditions, living was about liberating oneself or society from 'acting irrationally under the influence of emotions' (Oatley 2010, 31).

The enlightenment period too sought to gain a better understanding of the natural world through reason rather than through divine inspiration. This period was characterised by a “turning away from tradition, 'irrationality' and 'superstition' and towards 'scientific' and 'reasoned' thought in the quest for human progress" (Lupton 1998, 78). One of the benefits of this age of science is man's ability to identify causes, effects and even predict future happenings. Better living conditions and choice that have been associated with the rise of science during the industrial revolution are undeniable. Perhaps, better choice of a child's school as a result of an intellectual work by Ofsted inspectors is not bad after all. It needs to be said that this European social narrative of turning away from the irrationality of emotions stand in contrast with what was ascribed to the black man, for example, who was thought to be 'highly embodied, particularly sexually, and infantile and emotional compared to the white man' (Ibid 81). Despite the subsequent 'rejection of rationality' during existentialism movement (Solomon 1992, 611) and the realisation that emotions are at 'the core of human existence, underpinning systems of meaning and values' (Lupton 1998, 89), 'the notion that emotions are disruptive and somehow external to self remains dominant in contemporary Western societies' (Ibid 84). The theoretical framework for emotions to be introduced shortly and this study's findings show that emotions are constitutive of the 'rational' organisational activities and perhaps managed, in the case of inspecting schools, to the detriment of the much needed school improvement. Before elaborating on the framework and the research findings, it is essential to discuss what the literature has to say about emotions during school inspection.

\section{Emotions during school inspections}

Proposition 4: When emotions are discussed in the context of inspections, they often refer to the emotional impact Ofsted inspectors/inspections have on those they inspect: teachers and headteachers (Brimblecome et al 1995; Jeffrey and Woods 1996; Maden 2001b; Perryman 2007, 2009; Tunç et al. 2015). Jeffrey and Woods' (1996) study of a primary school staff showed that Ofsted's technicist or rather intellectually mechanical approach left teachers anxious, confused and deprofessionalised. Perryman (2007, 173), for example, captures the magnitude of those emotions by arguing that: 
the negative emotional impact of inspection on teachers goes beyond the oft reported issues of stress and overwork. Teachers experience a loss of power and control, and the sense of being permanently under a disciplinary regime can lead to fear, anger and disaffection.

While it can be imagined that this negative emotional phenomena would only affect those schools that are underperforming and fearfully feeling the need to stage an 'enacted fantasy' (Ball 2003) or 'fabricated performance' (Perryman 2009), positive inspection reports do not seem to have the opposite effect of lifting people's spirits (Maden 2001b). When describing the overall mood during inspections, Perryman $(2007,176)$ says: 'the inspection process seems quite benign'. The fact that Perryman goes on to highlight intense preparation for inspections, the fears and threat, is further evidence of the emotions felt by those being inspected. Whether the general feeling of Perryman's reported inspection (s) being 'benign' represents a significant development or shift from the tense and anti-climax feelings reported earlier (Brimblecome et al. 1995) is yet to be determined. The discussions around propositions 2 and 3 can be used to explain why literature on inspections has avoided discussing inspectors' emotions. Inspectors who are viewed as 'immune' from the vulnerabilities of emotions have, in the case of Perryman (2009), been discussed within a Foucauldian theoretical perspective of people whose specialist knowledge makes them powerful. In this study, the role of inspectors' emotions during inspections draws from Ashforth and Humphrey's (1995) framework that is discuss next.

\section{The theoretical framework for the study}

Solomon $(1992,611)$ has demonstrated that the philosophical dualism maintained between emotions and rationality is rather misleading since 'if an offense is worthy of anger, it becomes rational to be angry over it...' He goes one to rightly conclude that 'concepts and judgements that are constitutive of our emotions are in turn constitutive of the criteria for rationality as well' (Ibid). There are, therefore, implicit processes of emotions during explicit processes of rationality (Lacewing 2015) in the same way that there are implicit processes of rationality during explicit processes of emotions that include intuition. Moral intuition, which has been described as 'the sudden appearance in consciousness of a moral judgment, including an affective valence (good-bad, like-dislike), without any conscious awareness of having gone through steps of searching, weighing evidence, or inferring a conclusion' (Haidt 2001, 818), is not the primary concern here since this study traces the role of emotions within the 'rational' processes of searching for evidence, weighing and inferring conclusions during school inspections. 
According to Turner and Stet (2006), the sociological functions of emotions have been framed from a dramaturgical (concerned with how culture regulates the experience and expression of emotions in given situations), symbolic interactionist (focussed on emotions for conceptions of self and identities), interaction ritual (interested in the functions of emotions generated in cultural events of groups with shared values), power and status (focussing on the emotional generative effects of power and status), and exchange (studies emotions generated following rewards and punishment) theoretical perspectives. This study's interest in inspectors' reflections on how they managed their emotions during inspections places it within the dramaturgical research traditions. Here, Ashforth and Humphrey's (1995 also cited by Mosainder et al. 2016, 967) typology is particularly useful in conceptualising the mechanisms that organisations deploy to regulate the display of emotions that they view as 'the antithesis of rationality'. Notwithstanding an inspector's emotional competencies/skills (Goleman 1998; Goleman et al. 2013), such institutions, Ashforth and Humphrey (1995) argue, seek to neutralise emotions by multiplying processes of rationality; to buffer by delineating rational activities from emotional ones; to normalise what is unavoidable emotions by portraying them as undesirable and to prescribe acceptable emotional expressions.

While Ashforth and Humphrey's typology remains the guiding theoretical framework, investigating the role of emotions while inspecting schools within an institution like Ofsted that (as discussed when making the case for proposition 2) is guided by processes of rationality that seek to neutralise emotions means that, the study will develop individual inspectors' selfprescribed approach to managing emotions. Whether they go far enough to meet Ofsted's goals of ensuring accountability as well as improvement is another matter. Hence, the research question 'to what extent do inspectors' emotions form part of the inspection process within accountability regime of neo-liberal project and what lessons could be learnt nationally and internationally from this research project?

\section{Methodology}

This interpretivist small scale study is based in the North of England. It draws from interview data of 2 participants whom the author had come to know through the help of a university colleague and had formed part of an earlier doctoral study about the participants' experiences of school leadership. 'I feel for school heads during Ofsted inspections' was one of the comments from one of the participants in that earlier study that ignited the curiosity to explore the place of emotions during Ofsted inspections. Following those first encounters, subsequent 
meetings were arranged in 2014 to explore their experiences of inspecting schools as a separate topic.

Participants, to be referred to hereafter as P1 and P2, held different teaching and leadership positions before their appointments as primary school heads between the late 1990s and early 2000. During some years of their headship they also worked as inspectors before making a complete career move either as school improvement officer initially, or independent Ofsted inspectors straight from headship. At the time of the interviews, one of them had just retired as a lead inspector while the other still worked as a part-time Ofsted team inspector. The participants did not only know each other but they regularly discussed their work experiences. Their unique backgrounds provide this study with a rare insight from these insiders who were once outsiders on the receiving end of inspections, as it were. The focus here is on their insiders' experiences as inspectors in order to understand the place and role of inspectors' emotions during a school inspection. Their outsiders' experiences on how they, as school heads, would have experienced Ofsted inspections are not explored as it does not constitute the main focus of this paper. However, the literature review is, in effect, the outsider's view, that of the inspected.

Given the participants' proximity in their professional as well as private lives, the researching author felt the need to negotiate personal spaces and times, in their home, for clear in-depth personal views about their professional work to emerge. Those views were crossreferenced for convergence and/or divergence. They agreed that parts of a 2 hour-long recording from earlier interviews for a separate study could be used which helped to enrich and clarify their positions further.

Otherwise the research on which this paper is based draws mainly, but not exclusively, from another 2 hour-long in-depth interview recordings of P1 and P2 talking about 1) their intentions for becoming Ofsted inspectors and 2) what it is like when inspecting schools. This second focus draws from narrative research (Bold 2012) as it invites the participants to share the sequence of events when inspecting a school, the temporality, and the causation of events and the experience of inspecting schools. The extensive data collected and presented does offset the slim sample size for a topic like emotions that is not officially recognised by Ofsted as an institution. Bold $(2012,122 \& 1223)$ argues that 'one of the interesting features of narrative interview analysis is that interpretation begins in the researcher's mind during the interview'. Therefore, the next section will be an intersection of the findings with the analysis of the data 
that was coded to abstract themes (Riessman 2008) that are represented by extracts that feature here.

\section{Findings and analysis}

The findings are presented in the same way that they were researched (in two parts): (a) the intention for becoming an Ofsted inspector and (b) the process of inspection.

(a) Intentions for becoming Ofsted inspectors

Two themes emerged here. The participants cited the following as their intentions to become Ofsted inspectors:

(1) Acquisition/development of skills (for an inspector as an individual) and

(2) Organisational change (referent organisation being Ofsted).

With regard to the first theme, $\mathrm{P} 1$ evoked the necessity to develop the necessary skills required to cope well within educational organisations (schools and others) with the following words:

'I saw it as professional development, also to get into other organisations as well. When trained in a framework and apply it, you understand it in a deep way'.

The above extract undoubtedly puts an emphasis on the induction or training processes of Ofsted inspectorate. The impact of that induction, one would imagine, is primarily about the acquisition and development of skills for individual career development and the school (s) by association. The following assertion by P1 'you understand it in a deep way' points to the need for further research to ascertain the impact of Ofsted induction processes on inspectors' agency. The comment can be subject to all sorts of interpretations ranging from a simple understanding, through internalising to dogmatising of the process. What this study can say is that the content of what is whether understood, internalised or dogmatised is the process of inspection itself:

I thought that having been on the receiving end in the early days when I was a headteacher, I felt that clearly I wanted to do something about my school and one way of doing that is to understand the process (P2).

As already said, being inducted into the Ofsted's way of doing things could be perceived as passive. This however needs to be placed alongside the need to change Ofsted as an institution which constitutes the second theme when discussing intentions for becoming an 
Ofsted inspector. The 'get-formed and reform' agenda which brings the inspectors' agency to the fore was explicitly expressed in the following extract:

it may sound a little bit presumptuous but it was my feeling at that time that if we were stuck with Ofsted and it was to get better in its aim of helping schools to improve the more people joined Ofsted from a working knowledge potentially the better Ofsted would become in the way it carried out its investigations (P2).

To reform Ofsted by increasing its working knowledge capital has regained currency since the 2012 Ofsted framework. To what extent the overly intellectualised nature of Ofsted inspections would get reformed needed to be articulated. In principle, both P1 and P2 confirmed the narrative of inspection process being about emptying oneself of everything else other than reason. Despite the intention to bring school working knowledge to reform Ofsted, it soon became working knowledge realignment on the terms of Ofsted:

As an inspector, you have a code of conduct you abide by; you are there to professionally apply the criteria of the framework impartially, objectively, clearly and robustly. I think you get an insight into what that actually means if you are actually doing it rather than sitting and reading (P1).

In terms of the overly rational nature of Ofsted, it would seem that nothing has changed here. Instead, it is the same thing repackaged with familiar faces that the heads and teachers will have to connect with.

\section{(b) The process of inspection}

How long does an inspection team need to stay in a school in order to effectively account for a school's performance and help it improve is like asking how long a piece of string is. The inconclusiveness of such an issue is reflected in the move from a full week inspection with 2 months' notice to 2 or 3-day inspection with a day's notice. However long they take, the intellectual work of evidence gathering seems to begin prior to the inspectors setting foot on school premises as the following extracts illustrate:

I'm a team inspector: not paid to do any preparation but I do prepare. Lead inspector would send me a commentary, a letter of introduction that would tell me about what is in raise online, and if there are any issues in the school that I need to know about. I'm formally briefed but I also do my own research. I look at the previous Ofsted report, look at raise on line myself, look at the website, I can get a lot of information from school website: structure, organisation, who the head is, who governors are, nursery/primary, how they spend their pupils premiums, curriculum, how they relate to parents. I like to have a context of the school (P1). 
The team inspector, in this study, seemed to duplicate or engage in a similar process of evidence gathering:

Part of the preparation now is for me to look carefully at the raise online because that is where there is official record of students (standards and progress). There are different things of course but it presents a record going back 3 or 5 years. Before I go to that school, I can form a view about it; get a general picture of progress. Yes, as teachers, we know that some year groups perform better than others for all sorts of complex reasons but you get the big picture if you like, how the children at various key stages are doing $(\mathrm{P} 2)$.

The intellectual search for logical and coherent evidence is accelerated during the course of the inspection itself as reflected in the following extract:

While leading this inspection, I'm drawing on information from my team. Right, the look of the progress is going this way, is that consistent with what we are seeing out in the quality of teaching in classrooms, do these two things make a coherent picture? Or are there mismatches here and it's when we get mismatches that we have to dig down to the next level if you like (P2).

The institutionalisation, duplication, and acceleration/intensification of these 'rational' accountability searches/processes could be viewed as inspectors' attempts to commit to Ofsted's structural mechanisms to neutralise emotions (Ashforth and Humphrey 1995; Moisander et al. 2015) in order to avoid error in making judgements (Lacewing, 2015). However, at the centre of these attempts to research about schools to be inspected and gather the evidence before and while inspecting schools, all of which are intellectual activities, is the emotional experience which, arguably, is not the 'darker side' (Ball 1987, 270) but rather the 'other side' of inspections. Those emotions can be categorised as:

\section{(1) Emotional self-awareness}

(2) Empathy and trust building and

(3) Active emotional register.

Having been inspected during their headship years, there is an emotional self-awareness of what inspections do to people:

I suppose it's not easy thing to think that Ofsted is coming and they will judge you, there must be an element of stress there. But the framework has changed, and there is much more involvement from heads and in some ways heads can be influential in determining how the inspection process goes (P1).

Needless to reiterate the fact that the scope of this small scale study was defined along the lines of emotions or the affective side of inspectors being part of the inspection process and not the 
leadership experiences of P1 and P2. However, without putting words into the respondents' mouths, it is legitimate to suggest that in the background, as shown by the above extract, lurks not only an acknowledgement of the stress that inspections bring on the inspected but also an appreciation of intense stress that they would have experienced in their roles as primary school heads. It may emphasise the need for inspectors to have some background experience of school leadership. That said, the 'how would I feel if put in the same situation' or what I term emotional (self) awareness approach that P1 shows in the above extract is not an exclusive domain of inspectors with a school leadership background.

The inspector may wish to empty him/herself of anything other than reason deemed necessary for inspections, but the reality on the ground is different. Their emotions and emotional intelligence are not left at the school gates; they are part and parcel of the inspection process. The data gathered for this study suggests that there are some attempts to empathise

\section{and build trust:}

It's impossible to take all of the pressure out of the inspection, because it is the time of reckoning isn't it, by definition! But I want those teachers to feel as comfortable with the process as it is reasonable possible, therefore to perform as teachers in as natural as is reasonably possible. So, I always say 'this is well intentioned, we are not here to cause you undue pressure or stress, we want to see you teach in the way that you would normally teach, if you have any concern, you come and talk to us about that and we will sort that out. We are happy to give you professional feedback after observation or later'. It's all about trying to put people at their ease, at least to instil some belief that we are there to do good rather than harm (P2).

This can of course be subject to interpretations and may not be enough to calm teachers and head teachers' nerves. Whatever the effects of the (lead) inspector's projected positive emotional signal on the staff to be inspected, the inspectors continue to activate their nonformal (in that it is not stipulated in Ofsted framework) and self-prescribed emotional register or receptor of the ambiance of the schools being inspected:

You do definitely get a sense of the place very quickly after you walk in. It's not just about behaviour in the normal received sense, whether the pupils behave well or badly. It's the way pupils comport themselves, it's intangible, there is something in the air, you can sense a feeling of pride, a feeling of belonging, a feeling of community, where those things exist. The converse sadly is that you can feel a lack of those things where those things don't exist (P2).

The intangibility expressed by $\mathrm{P} 2$ is clarified further by $\mathrm{P} 1$ when giving a list of affective perceptions: 
I mean I can take you to a school and you can suss it out fairly quickly. Without a framework, you would sense if this is up here somewhere, or this is ok, or this is ok but... (P1).

The 'sussing' of the school seems to happen at two levels. There are the direct and indirect affective perceptions. The direct perceptions are those that an inspector grasps directly from entering the school, meeting students and observing:

There isn't any criterion that talks about emotions, not in the framework at all. But as a professional, you can sense when you go into a school, who is greeting you, what's like in the sign book, is there a pen there, what's that procedure like? Who is waiting to receive you when you get there? So all these things are indicators aren't they?

The essence of the above citation can be interpreted differently. In an era of austerity, school leaders who are expected to meet various expectations on tight budgets might question the legitimacy of emotional perceptions that attach a greater importance on additional expenditure to make inspectors 'feel good' during the process of inspection. The spirit of this direct emotional experience can, however, be summed up in the following:

If it is welcoming us, you can assume it welcomes everybody. If it cares for us, in terms of helping us to do our job, or making sure you have got lunch...it is highly likely they will translate that care and concern around their pupils, their students and their staff. There is a technical thing about the framework, about the inspection but there is also an emotion because you know that if I'm feeling happy, secure, safe, it is highly likely children are feeling happy and safe. If I'm feeling an element of freedom to move around where I'm want to move around when like it, it's highly likely children will feel there same way too. And you can certainly sense. We do talk about this is a happy school. These teachers love teaching in this school. We use that, we can't use that in the Ofsted report but we use that language (P1).

It is more of a culture of care, hospitality, freedom, safety etc., which are reserved in a nonexclusive way to inspectors. In the light of this, the English and non-English school leader could, therefore, re-examine their cultural traditions that would enhance direct emotional perceptions of inspectors.

The indirect affective perceptions however are those that are acquired as a result of discussions about direct perceptions of inspectors.

The first conversation you have at break time; you may ask: what strikes you about this school? Eh, where I have been, obviously people love teaching here and teaching assistants are keen, they are a key driver in this school, or there are some tough children in this school, really difficult children but wow, they are on them aren't they? They are challenging them; they are supporting them. You can 
similarly come back and say, how has it been for you this morning? And say, I'm actually bored stupid. And if I'm bored, children are bored... (P1).

The above two extracts are examples of how both direct and indirect emotional perceptions can lead to the formation of a judgement about the performance of a school. However, the order can be reversed. When the (re)searched positive indicators about a school do not match, the emotional register is ignited, this time, in a search for improvement. The dialogue below is testament to the joint effort to evidence improvement that, I believe, should be taken further to create improvement even for the struggling schools.

Let's take a possible scenario here, I (the inspector-my italics) have looked at the data beforehand and it's strong, the school appears to be doing a cracking job. I go into the school and all of this stuff about the way that pupils comport themselves, the way that staff interact with pupils, something right is going on in this building. And yet, when I start to look at individual lesson observations, though we talk about other things, the single biggest thing is to get through as many lesson observations as we can. If that isn't quite stacking up, you might say to the head, look this is certainly a good school and my sixth sense tells me that this is potentially an outstanding school but we haven't got the evidence. Where could we possibly go? Tell me! (P2).

The dialogue, in this case, is cemented by the positive response given by the other party as P2 illustrates in the second part of the scenario:

You (the headteacher-my italics) say: well you have to see $\mathrm{X}$, you have to see our so and so. You need to go back to this teacher, and he/she will give you an outstanding lesson... (P2).

The above scenario reveals another important emotional aspect of school inspections. That, direct and indirect emotions do not occur in a historical vacuum. They build up from earlier research/knowledge about a given school. If that historical emotion is good as evidenced by the words 'the school appears to be doing a cracking job' (P2), what followed in this case was 'emotional flexibility' on the part of the inspector. While such flexibility should be encouraged, there is also a danger of creating an inspection divide where good historical emotions lead to emotional flexibility that would afford certain schools additional chances to evidence improvement on the one hand; while bad historical emotions could lead to emotional antipathy towards schools in challenging areas and presumably not 'doing a cracking job' on the other hand.

But even in the case of a good school, as P2's scenario suggests, it is essentially a dialogue between unequal partners where the stronger party, the inspector in this case, 
has the last word as to how far his/her emotions, either for accountability or improvement, are pursued:

If the things that you have put on the agenda work for you then it's highly likely that your school is going to come out as an outstanding school. But what I cannot do is corrupt the evidence (P2).

'But what I cannot do is corrupt the evidence' reveals the thinking behind the limits of the agency of the two inspectors interviewed and the need they felt to control their emotions at this critical stage of the inspection. While some feelings lead to the search for evidence, others had to be suppressed as the following extract shows:

I cannot let my emotions take the day. I may have been having a very positive emotional response during that inspection, but in the end I have got to follow the criteria and if the evidence does not stack up to that then, there is nothing I can do about it (P2).

Although these inspectors broke with Ofsted tradition of neutralising emotions, their selfprescribed emotional responses were buffered or compartmentalised (Ashforth and Humphrey 1995) into acceptable emotions (to be followed up on) and those that are not acceptable (and therefore to be suppressed). It is argued here that those that are allowed to be experienced by the two inspectors interviewed here are mainly emotions for accountability. They are first acknowledged simply as a way of understanding the pressures that heads and teachers might be experiencing. Those inspectors who choose to address the staff in an attempt to calm their emotions create an environment that would allow the school to give an account of their day-today performance against the inspection criteria. Inspectors' emotional registers are then activated and act as evaluative sensors. Hence, an inspector's feelings about the overall mood might give them an idea about the quality of leadership as the following extract illustrates:

where I have been, obviously people love teaching here and teaching assistant are keen, they are a key driver in this school, or there are some tough children in this school, really difficult children but wow, they (meaning teachers and leadershipmy italics) are on them aren't they? (P1).

Feelings for accountability are summative and rooted in the present with a view of what the past daily routines of a school's efforts to build a culture for learning (through school ethos and how the curriculum feeds into that ethos) and how that informs inspectors. Emotions for improvement, however, are formative and based on the need and ability to affect future practices. If not suppressed, they require a certain degree of agency on the part of inspectors to translate them into action. 
The expectation is that the teacher finds the inspector. I give feedback when I can, so if I'm finished about break-time and I see a teacher in the classroom, I would pop in and say would you like some feedback? Would you like it now, I don't want to interfere with your break but if you'd like it now, I'm happy to do it (P1).

The agency on the part of an inspector can be an opportunity to give practical guidance on how to improve classroom practice for a possible second classroom observation or for the future:

When we give feedback, we talk about the strengths and areas for development. If you have somebody that is outstanding, I'd start with: the strengths in this lesson outweigh the weaknesses. The quality of learning is outstanding because the quality of your teaching is outstanding and that leads to behaviour and safety. If not outstanding, requires improvement...we are supposed to recommend something about their teaching that could actually move their teaching up to the next grade. So I say, this was a good lesson because...if you want to make that outstanding, one thing you may want to consider is... and it could be anything as little as: the children that are more able didn't have to do the same amount of work, they could have come in at a higher level which would move them quicker and do an extension task...that could move your teaching from good to outstanding... or it could be about the way the teacher understands prior learning, or uses questioning in a more directed way to different pupils (P1).

This reverses the opinion that one (an inspector) cannot do anything to improve what they see while inspecting schools. And if what is observed is felt as reflecting normal day-to-day practice as the following extracts implies;

I have been in situations where people have dropped their game, an outstanding teacher, whose lesson is judged as good. They request another observation... we have a conversation about: are you sure this is a wise thing? Because, I have seen a drop lesson, and I am seeing something that is inherent, I think I can call that. (Feeling for accountability-my italics) (P1)

Then, it is in the interest of achieving improvement that feelings for improvement are pursued and not suppressed through talking oneself or schools out of them:

'What if we go back and the same thing happens or worse, what will it do the teacher... the schools have understood and have said, actually you have a point there'.

While the caring approach that can be seen in the above extract cannot be disputed, it diminishes schools' chances to demonstrate any 'inherent' ability for improvement that they may have which could sway an inspection judgement in the same way emotions for accountability are given expression. When given expression, feelings for improvement can be pursued without it becoming professional malpractice on the part of inspectors as the following extract suggests: 
But what I cannot do is corrupt the evidence...I wouldn't be doing my job properly if I said well just right a couple of bogus forms and write outstanding on the bottom and we'll probably get away with this. It's unthinkable (P2).

Ethical conduct is essential but there is a sense here too that feelings for accountability filter through while fully ethical actions based on emotions for achievement are not distinguished from acts of corruption.

\section{Implications}

Despite the participants for this study acknowledging their individual interests and conflicts/struggles which made them choose to join Ofsted, such interests either coincided with those of Ofsted or, since 'the habitus tends to adjust to new fields automatically...' (Chandler 2013, 472), those interests were integrated in the 'economy of practices' (Bourdieu 1990, 50) of Ofsted. The first implication therefore relates to whether there can be a real rapprochement between schools and Ofsted without the latter absorbing the former into its own (presumably rational) practices as the following extract illustrates:

The story in the inspection report has to be cross-referenced with the evaluation schedule ... Those things are cross-referenced by people at Ofsted to make sure that those links, the links between the criteria and the evaluation schedule and report are solidly in place. Now, if I said to you that an emotional response has never swayed and inspection, I would not be telling the truth (P2).

Linked to the first implication is the difficulty it would pose to overcome the (false) public image of school inspections being about rationalised processes. Greenfield's $(1986,61)$ position with regard to, what could be said, the neglect of human emotions comes through in the following words:

We have a science of administration (or inspection -my italics) which can deal only with facts and which does so by eliminating from its consideration all human passion, weakness, conviction, hope, will, pity, frailty, altruism, courage, vice and virtue...in its own impotence, it is inward-looking, self-deluding, self-defeating, and unnecessarily boring.

The elimination of emotions (Ibid) or their neutralisation (Ashforth and Humphrey 1995) has been exemplified here by the institutionalisation, duplication and intensification of rational searches/processes prior to and during inspections. However, the 'silent' presence of feelings and emotions as a constitutive dimension of inspection processes, at least of the inspectors on whom this study is based, needs to be acknowledged. In the light of this, Clarke's (2008) social paradox argument that is built on the premise that the identities, interests and (emotional) experiences of inspectors compromise Ofsted's claimed independence calls for further 
theorising of the concept of 'independence' that takes into account an earlier view from Solomon $(1992,611)$ that 'judgements that constitutive of our emotions are in turn constitutive of the criteria for rationality as well'.

The suggestion here is that emotions do not inhibit but they, instead, have the potential to illicit independent judgements that could move inspections from being an exercise for accountability to that of improvement. This is easier said than done. It is the case that inspectors in this study have acknowledged their self-prescribed emotional competencies of selfawareness, empathy and trust building. However, through direct and indirect registering and accounting of their emotions, at times, tinctured with positive or negative historical emotions of a given school, the inspectors were able to buffer 'emotions for accountability', which they chose to pursue, and 'emotions for improvement', that they elected to supress. This has implications on (Ofsted) inspectors' ability to be agents for school improvement right from the time of inspections.

There is also the need to have a debate on the professionalism of an inspector. Despite acknowledgement that emotions affect the business of inspecting, inspectors' deliberations about what is and what is not a permissible emotion can define the professionalism of some within Ofsted as indicated in this expression '...I wouldn't be doing my job properly if...' (P2) used to justify the regulation of emotions during inspections. How inspectors interviewed here used their emotions even though such talk is not recognised by Ofsted is already an indication that the traditional ethical code of 'positivistic and rule-bound framework which informs a prescriptive and disciplinary approach to professional behaviour' (Lunt 2008, 88) is unsustainable. There is a dialogue already happening between school heads and inspectors during inspections:

England and Styria also describe how communication between head teachers and principals during inspection visits may enhance the school's capacity to improve. The head will often accompany the inspectors as they observe lessons. A dialogue will occur between the head and the inspector in order to gauge whether the two of them make the same judgments as each other. This can amount to mentoring the head by explaining how, for example, the head may use the inspection classroom observation scheme to supervise and observe teachers (Ehren et al 2013, 24).

Perhaps future inspector-inspected dialogues should not shy away from expressing and acting on feelings for improvement in order to bring that wished for inspector and inspected partnership (Baxter 2014) to bear. 
The value of emotions during school inspections may have, perhaps for the first time, found a voice in this research but the pertinence of emotional intelligence in social interactions is not new (Goleman 1998; Goleman et al. 2013). What remains underexplored, however, is the extent to which cultural narratives about emotions (and intellect) could modulate potential emotions for accountability and emotions for improvement during school inspection practices in England and around the world.

\section{References}

Ashforth, B.E. and R.H., Humphrey. 1995. Emotion in the workplace: A reappraisal. Human Relations, 48: 97-125.

Ball, S.J. 1987. The Micropolitics of the School. London: Routledge.

Ball, S.J. 2003. The teacher's soul and the terrors of performativity. Journal of Education policy 18 (2): 215-288.

Ball, S.J. 2007. Education Plc: Understanding Private Sector Participation in Public Sector Education. London: Routledge.

Barret F. L. 2006. Solving the emotion paradox : categorisation and the experience of emotion. Personality and Social Psychology Review 10 (1): 20-46.

Baxter A. J. 2014. An independent inspectorate? Addressing the paradoxes of educational inspection in 2013, School Leadership \& Management: Formerly School Organisation 34 (1): 21-38.

Baxter, J., and J. Clarke. 2013. Farewell to the Tick Box Inspector? Ofsted and the Changing Regime of School Inspection in England. Oxford Review of Education 39 (5): 702-718. doi:10.1080/03054985.2013.846852.

Binali, T., İ. Yusuf, G. Bülent. 2015. Inspection and teachers'emotions: An emotional evaluation of inspection. International Journal of Human Sciences 12 (1): 554-568.

Bold, C. 2012. Using Narrative in Research. London: Sage.

Bourdieu, P. 1990. The Logic of Practice, Richard Nice (Trans). Stanford: Stanford University Press.

Brimblecombe, N., M. Ormston, and M. Shaw. 1995. Teachers' perceptions of school inspection: a stressful experience. Cambridge Journal of Education 25 (1): 98-108.

Brundrett, M. 2014. Social justice and fairness in primary education: the case for a more ecological view. Education 3-13: International Journal of Primary, Elementary and Early Years Education 42 (1): 1-4. 
Butler, A. E., L. L. Tiane, and J. J. Gross. 2007. Emotion regulation and Culture: are the social consequences of emotion suppression culture-specific? Emotion 7 (1): 30-48.

Centre for British Teachers Education Trust, Inspecting Government schools, accessed at http://www.cfbt.com/en-GB/What-we-do/School-improvement/School-inspection-andreview/Inspecting-government-schools on 14/11/2015

Chandler, B. 2013. The subjectivity of habitus. Journal for the Theory of Social Behaviour 43 (4): 469-491.

Chapman, C. 2001. Unlocking the potential: inspection as a mechanism for school improvement. Improving schools 4 (3): 41-50.

Clack, J. 2008. Performance paradoxes: The politics of evaluation in public services. In: D. Howard and S. Martin, S. (Eds). Public Services Inspection in the UK. 120-134. Reserach Highlights in Social Work (50). London: Jessica Kingsley Publishers.

Clarke, J. 2013. "What is Public in Public Policy: Embodying the Public Interest: The Case of School Inspection." Paper presented at the International Conference in Public Policy, Grenoble, June 26-28.

Dedering, K. and S. Muller. 2011. School improvement through inspections? First empirical insights from Germany. J Educ Change 12: 301-322.

E Hert T, K. Titeca. and I. Wagemakers. 2012. Make schools, not war? Donors re-writing of the social contract in the DRC, Development Policy Review, 30 (6): 681-701

Ehren, M.C.M., Altrichter, H., McNamara, G. and O'Hara, J. (2013). Impact of school inspections on improvement of schools-describing assumptions on causal mechanisms in six European countries. Educ Asse Eval Acc 20 (1): 3-43.

Ehren, M.C.M. and A.J. Visscher. 2008. The relationship between school inspections, school characteristics and school improvement. British Journal of Educational Studies 56 (2): 205227.

Goleman, D. 1998. What makes a leader? Harvard Business Review.

Goleman, D., R. Boyatzis. and A. McKee. 2013. Primal Leadership: Unleashing, the power of emotional intelligence. Boston, Massachusetts: Harvard Business Review Press.

Goodson, F. I. 2013. Developing Narrative Theory: Life Histories and Personal Representations. London: Routledge.

Greenfield, T.B. 1986. The decline and fall of science in educational administration. Interchange 17 (2), 57-80.

Gurkan T and A. Deveci. 2012. Comparison of the education inspection systems in Turkish Republic of Northern Cyprus, Turkey and U.K (England). Procedia-Sosial and Behavioural Science 47: 651-655. 
Haidt, J. 2001. The emotional dog and its rational tail: a social intuitionist approach to moral judgment. Psychology Review, 108 (4):814-834.

Jeffrey, B. and P. Woods. 1996. Feeling deprofessionalised: the social construction of emotions during an Ofsted inspection, Cambridge Journal of Education, 26 (3): 325-343.

Jones, K. and P. Tymms. 2014. Ofsted's role in promoting school improvement: the mechanisms of the school inspection system in England, Oxford Review of Education, 40 (3): 315-330.

Lacewing, M. 2015. Expert moral intuition and its development: a guide to the debate. Topoi, 34 (2): 409-425.

Lee, J. and J. Fitz. 1997. HMI and Ofsted: Evolution or revolution in school inspection, British Journal of Education, 45 (1): 39-52

Lunt, I. 2008. Ethical issues in professional life. In Exploring Professionalism, In Cunningham, B. (Ed), 73-98. London: Institute of Education, University of London.

Lupton, D. 1998. The Emotional Self. London: Sage.

Maden, M. (Ed.). 2001b. Success Against the Odds: Five Years on. Revisiting effective schools in disadvantaged areas. London: Routledge Falmer.

Maclure, S. 2000. The Inspector's Calling. Oxford: Hodder and Stoughton.

Matsumoto, D., H.S. Yoo. and J. Fontaine. 2008. Mapping expressive differences around the world: The relationship between emotional display rules and individualism versus collectivism. Journal of Cross-Cultural Psychology 39: 55-73

Meikle, J. Feb 22, 1992. Opposition mounts against the 'folly' of privatising inspectors' work, The Guardian

Moisander, J., H. Hirsto and K. Fahy. 2016. Emotions in institutional work: a discursive perspective. Organisation Studies 37 (7): 963-990.

Office for Standards in Education (Ofsted). 1999b. Handbook for Inspecting Primary and Nursery Schools. London: The Stationery Office.

Office for Standards in Education. 2012a. The Framework for School Inspection. London: Ofsted.

Office for Standards in Education. 2013. How to become an inspector (HIM-Her Majesty's Inspector). Accessed at: http://www.ofsted.gov.uk/about-us/working-for-ofsted/how-becomeinspector, on $24^{\text {th }}$ December 2013.

Office for Standards in Education. 2014. The Framework for School Inspection. Accessed at www.ofsted.gov.uk/resources/120100 on 8th March 2014.

Oatley, K. 2010. Two movements in emotions: communication and reflection. Emotion Review 2 (1): 29-35. 
Palmer, W. P. 1990. Nationhood and Education in Nigeria: A Case Study of School Inspection in Nigeria as a means of increasing Central Government Control, In Nationhood, Internationalism and Education (Edited Roger Peddie), Proceedings of the Eighteenth Annual Conference of the Australian and New Zealand Comparative and International Education Society from 3rd- 5th December, O'Rorke Hall, University of Auckland, New Zealand, pp. 171-184.

Perryman, J. 2007. Inspections and emotions. Cambridge Journal of Education 37 (2): 173190.

Perryman, J. 2009. Inspections and the fabrication of professional and performative processes. Journal of Education Policy 24 (5): 611-631.

Richards, C. 2001a. School Inspection in England: An Appraisal Impact No. 8. London: Philosophy of Education Society of Great Britain.

Richards, C. 2001b. School inspection: a re-appraisal. The Journal of the Philosophy of Education Society of Great Britain 35 (4): 655-665.

Richards, C. 2012. Ofsted Inspection Inspected: an examination of the 2012 framework for school inspection and its accompanying evaluation schedule. Forum 54 (2): 247-272.

Riessman, K. C. (2008). Narrative Methods for the Human Sciences. London: Sage.

Rosenthal, L. 2004. Do school inspections improve school quality? Ofsted inspections and school examination results in the UK. Economics of Education Review 23: 143151.

Solomon, R. 1992. Existentialism, emotions, and the cultural limits of rationality. Philosophy East and West, 42 (4): 597-621.

Turner, J. and J. Stets. 2006. Sociological theories of human emotions. Annual Review of Sociology, 32, 25-52. 